\title{
Open Editors: A Dataset of Scholarly Journals' Editorial Board Positions
}

\author{
Andreas Nishikawa-Pacher, Tamara Heck, Kerstin Schoch \\ Correspondence to: andreas.pacher@tuwien.ac.at
}

\begin{abstract}
Editormetrics analyses the role of editors of academic journals and their impact on the scientific publication system. Such analyses would best rely on open, structured, and machine-readable data about editors and editorial boards, which still remains rare. To address this shortcoming, the project Open Editors collects data about academic journal editors on a large scale and structures them into a single dataset. It does so by scraping the websites of 7,352 journals from 26 publishers (including predatory ones), thereby structuring publicly available information (names, affiliations, editorial roles, ORCID etc.) about 594,580 researchers. The dataset shows that journals and publishers are immensely heterogeneous in terms of editorial board sizes, regional diversity, and editorial role labels. All codes and data are made available at GitHub, while the result is browsable at a dedicated website (https://openeditors.ooir.org). This dataset carries implications for both practical purposes of research evaluation and for meta-scientific investigations into the landscape of scholarly publications, and allows for critical inquiries regarding the representation of diversity and inclusivity across academia.
\end{abstract}

\section{Introduction}

Editors of scientific journals play an important role in the publication system: They legitimize selected research (Card \& DellaVigna 2020), oversee the academic peer review procedure (Horbach \& Halffman 2020), and influence the careers of scholars by (not) allowing them to publish in their journals (Zhang et al. 2021). Editorial decisions may sustain intellectual and societal biases (Petersen 2017); for instance, their judgements might be driven by homophily, or personal affections that favour colleagues they work with, who come from the same region, or who promote research approaches similar to one's own studies (Yoon 2013). But if 'scientific rewards are based [merely] on publications' (Crane 1967), then any favouritism granted by editors to individual researchers or specific groups might seem unethical (Laband \& Piette 1994). 
It is in this context that researchers have investigated the impact and consequences of editorial work by analysing the composition of academic journals' editorial boards (Mazov \& Gureev 2016), including in terms of gender representation (Feeney et al. 2019; Stegmaier et al. 2011; Topaz \& Sen 2016), international diversity (Espin et al. 2017; Gutiérrez \& López-Nieva 2001; Okagbue et al. 2018), economic inequalities (Horton 2003; Xu et al. 2019), social networks of researchers (Baccini et al. 2019; Brogaard et al. 2014; Erfanmanesh \& Morovati 2018; Goyanes \& de-Marcos 2020), the reputation of their institutional affiliations (Hodgson \& Rothman 1999; Petersen et al. 2017), and issues of publication ethics (Bishop 2020; Bornmann \& Daniel 2009; Wong \& Callaham 2012). They have also turned their eyes on predatory journals that wrongfully list reputable scientists as editors so as to heighten the journals' prestige (RuiterLopez et al. 2019).

Research evaluators might also be interested in such 'editormetric' studies (Mendonça et al. 2018). They may wish to gain an overview of the representation of scientists across scholarly outlets. They may want to identify the extent to which they are (erroneously) named as editors of predatory journals. They may want to assess the mentoring and community services that come with editorial workloads. They may want to consider the different roles, like chief editorships or peer review contributions, and relate them to Open Science practices: an editor of a journal that just transited to a 'Diamond Open Access'-model or that experiments with 'Open Peer Review' could obtain special recognition. Data about journal editorships can thus add important nuances to the scientific system - especially since ' $[\mathrm{t}]$ he choice by funders and institutions of what to measure for assessment directly influences research culture and behaviours' (European Commission 2021 p. 4). And instead of rewarding only 'a certain type of research outputs' - namely paper publications - research evaluation could draw from editormetrics to also acknowledge vital contributions in 'research as a process' (European Research Area and Innovation Committee 2021 p. 12).

Analysing the 'gatekeepers of knowledge' (McGinty 1999), however, comes with one major problem: the lack of structured data availability on scholarly journals' editors and editorial boards. While basic information about editors are available in the online presences of scholarly journals, the data are not uniformly structured and therefore not machine-readable - a major issue in the broader movement towards Open Data and Open Science as it relies on a quick processing of huge amounts of meta-scientific data (Aryani et al. 2020; Hendricks et al. 2020). 
To give an illustrative example, one publisher may list the editors by mentioning the given name first and the last name thereafter, followed by a comma and the editors' institutional affiliation, as in Jan Melissen, Leiden University, while another may first list a title (like Prof. or Dr.), then the last name with an abbreviated given name, followed by the institutional affiliation in parentheses rather than after a comma, as in Dr. Melissen, J. (Leiden University). The heterogeneous way of displaying information not only pertains to interpublisher, but in many cases even to intra-publisher differences. To name but one example, the publisher Taylor \& Francis shows editorial board details in different formats despite the journals belonging to one and the same publisher (Figure 1). In the case of Springer Nature, even the URLs linking to the information about the editors are heterogeneous, which makes automated data generation rather burdensome (see Table 1).

\begin{tabular}{|l|}
\hline $\begin{array}{l}\text { Journal } \\
\text { Central Asian Survey > }\end{array}$ \\
\hline About this journal \\
Editorial board \\
Editor: \\
Rico Isaacs - University of Lincoln, UK \\
\hline
\end{tabular}

\begin{tabular}{|l|}
\hline Journal \\
The Cartographic Journal > \\
The World of Mapping \\
\hline About this journal \\
\hline Editorial board \\
Editor: \\
- Dr Alexander Kent (Reader in Cartography and Geographic \\
Information Science, Canterbury Christ Church University, \\
Canterbury, UK) alexander.kent@canterbury.ac.uk
\end{tabular}

\begin{tabular}{|l|}
\hline $\begin{array}{l}\text { Journal } \\
\text { The Information Society > } \\
\text { An International Journal }\end{array}$ \\
\hline About this journal \\
\hline Editorial board \\
Editor-in-Chief: \\
Harmeet Sawhney \\
The Media School \\
Indiana University, Bloomington \\
\hline
\end{tabular}

Fig 1. Three journals from the same publisher (Taylor \& Francis) displaying information about their editors in three different ways, as of December 2020. - Left: Central Asian Survey. Centre: The Cartographic Journal. Right: The Information Society.

Table 1. Heterogeneously structured links leading to information about editors at four Springer Nature journals.

\begin{tabular}{lll}
\hline Journal & URL & Comment \\
\hline British Dental Journal & nature.com/bdj/about\#editors & URL contains a hash (\#) \\
Human Genome Variation & nature.com/hgv/about/editor & “editor” in singular \\
Bone Marrow Transplantation & nature.com/bmt/editors & URL does not contain the "about"-tag \\
Nature Cell Biology & nature.com/ncb/about/editors & “editors" in plural \\
\hline
\end{tabular}


As a consequence of the non-uniform data structure, every study that analysed the impact of journal editors and editorial boards relied on laborious processes of manual data collection (Baccini et al. 2019 p. 279; Petersen 2017 p. 258; Topaz \& Sen 2016 p. 4). Not only is this a highly time-consuming and monotonous task (Baccini \& Barabesi 2010 pp. 369-70; Xie et al. 2019 p. 1338) that only allows for a small sample size; but what is more, this approach offers 'just a snapshot in [a] specific moment' (Mendonça et al. 2018 p. 1518). The data collected, even if prepared properly and shared openly, get outdated quickly and thus are not appropriate for further re-use in research. Follow-up studies would need to manually generate the data again, hampering a reproduction of previous studies on editorial boards.

To mitigate some of those shortcomings, this paper presents an automated data-collection project called Open Editors. It utilizes webscraping to collect and provide a structured dataset of scholarly journals' editors and editorial board members. The data are freely available for any use under a $\mathrm{CC} 0$-license so as to enable large-scale analyses. The data collection will be performed on a regular basis through a scripted program whose codes are available in a public repository. In the latest release, Open Editors scraped the websites of 7,352 journals from 26 publishers (including five predatory publishers), comprising basic information about 594,580 editorial board positions.

The present effort goes hand in hand with other meta-scientific initiatives that systematically document key practices of journals and editorial guidelines. They often do so as grassroots projects crowdsourcing related data, such as with regards to peer review models (cf. S. Horbach \& Halffman 2018), preprint guidelines (Klebel et al. 2020; Nosek et al. 2015), or Open Access policies (Curry 2017; Marchitelli et al. 2017). Open Editors serves as an additional step in this broader effort to increase the transparency of the structure of scientific publishing through bottom-up data collections - at least as long as a centralized, top-down data-collection approach remains absent (Michaud 2022).

The following section outlines the methodical approach to generate the dataset in detail, followed by an explanation of how to access the data. The results section thereafter assesses the representativeness of the sample and presents some summary statistics regarding the overall dataset. It also outlines publisher-level data about editorial board sizes, highlights the immense pluralism regarding editorial role labels, and shows publisher-level statistics about the 
geographical distribution of the editors' affiliations with a special look at predatory publishers and at the Anglo-American shares represented in the editorial boards; all in all, the descriptive data indicate that the journal landscape is highly heterogeneous. The paper then discusses how Open Editors could aid in various editormetric analyses, including in investigations of diversity and inclusivity aspects as well as possible use cases for research evaluations and scientometric assessments. That section also points to various limitations and further desiderata, such as the challenging task of linking the dataset with persistent identifiers (PIDs), or the ethical problems that arise with using automated 'diversity guesser' tools. The paper finally concludes with a call to push forward the broader Open Science agenda of opening up more and more data about the scholarly publication process so as to enable a culture of inclusivity, transparency and knowledge equity across the system of science.

\section{Methods}

\section{Data Sample}

This method section outlines the approach taken for the release of Open Editors in early 2022. As the project intends to iterate the data collection annually, it is possible that future releases will add minor adjustments to enhance the approach and to enlarge the sample. New publishers were indeed constantly added to the dataset. All changes will be documented transparently through the version control system on GitHub (Pacher 2022) where all codes and data are available under a CC0 license.

As of mid-2022, Open Editors collected data about editors and editorial board members from journals belonging to 26 major publishers. The major criteria for the choice of publishers was that they provide data about journal editors in a homogeneous structure, thus allowing machines to read them without major difficulties.

The first 21 of these publishers were American Psychological Association (APA), American Society of Chemical Engineers (ASCE), BioMedCentral, Brill, Cambridge University Press $(C U P)$, eLife, Elsevier, Emerald, Frontiers, Hindawi, Inderscience, John Benjamins, Karger, Multidisciplinary Digital Publishing Institute (MDPI), PeerJ, Pleiades, Public Library of Science (PLoS), Royal Society of Chemistry (RSC), SAGE, and Springer Nature. In addition, five publishers known to be predatory were likewise included in the sample, namely Allied 
Academies, iMedPub, Longdom, Scientific Research Publishing (SCIRP) and SciTechnol; all of them but SCIRP are imprints of the larger predatory publisher OMICS, and both SCIRP and OMICS are widely known to host 'fake journals' (Masic 2017; Simón 2016).

The goal of this work is not primarily the inferential analysis of the data themselves but the development of a methodical tool that will allow scientists to gain samples for their research without the tedious process of manual data collection. The current subset is only the beginning and offers a convenient sample of an ultimately unknown population of publishers. We will nevertheless give a rough estimate of the dataset's representativeness by comparing it with the publication data as documented by OpenAlex, a new database covering meta-scientific information on a grand scale (Priem et al. 2022); and the discussion section will argue that for exploratory purposes, it is better to collect any available data based on a convenient sample than to not undertake any collection efforts at all.

\section{Data Collection: Webscraping}

Two data subsets were collected with regards to the 26 publishers: The first subset contains each of the publishers' journals as well as the URLs to the journals' editorial board information. The second subset contains seven variables pertaining to every editorial board member:

- the name (without disentangling titles, given names, middle names, and surnames),

- the institutional affiliation (if available, the research institute, often the university, at which the editor is employed),

- the ORCID ID (Open Researcher and Contributor ID), if available in a uniformly structured format (this only applies to journals from Hindawi, John Benjamins, PLoS and $R S C$ ),

- the editorial position (the role the editor occupies at the journal, such as 'Editor-inChief', 'Associate Editor' or 'Book Review Editor'),

- the journal name,

- the ISSN (if available on the same webpage as the information about editors),

- the publisher,

- the URL (containing a link to the scraped website),

- and the date of scraping (in the format YYYY-MM-DD). 
Open Editors mainly utilized the R library rvest (Wickham 2020) to fetch the data from the journal websites. For each publisher, a different code had to be used to adapt to their respective webpage design and structure. The webscraping process took place in early 2022.

\section{Data Presentation and Accessibility}

After the webscraping process, the data were structured into machine-readable files based on comma separated values (CSV). As a basic quality check, duplicate data that carried the identical values in the editor-, journal- and publisher-fields were eliminated, and incomplete data where both the editor and the affiliation remained unavailable during the crawling were removed as well. In addition, HTML tags, or codes that aim at layouting a given website such as by making fonts italic through the tag <i>, sometimes accidentally slipped into the dataset, and they were likewise deleted. All the remaining data were merged into a CSV-file and made available at GitHub under a Creative Commons license (CCO) so as to enable anyone to download the whole data dump without any restrictions.

In addition to the CSV-data dump, Open Editors also created a website that enables access to the data via a form with which end users can search for names, journals, or institutional affiliations. For that purpose, the collected dataset was put into a MySQL database. The website is available at https://openeditors.ooir.org. As an example, users can type in "University of Salzburg" into the search bar to find a list of all editors in the dataset who have "University of Salzburg" in their names, affiliations, or journal name. The search function also supports basic Boolean operators such as AND, OR, NOT, brackets, and quotation marks. For instance, the query "Salzburg AND (Biology OR Geoinformatics)" would look for all data that contain "Salzburg" and either "Biology" or "Geoinformatics".

Note that a variant of the code at GitHub - added ex post by Bianca Kramer from the Utrecht University Library - allows one to loop the affiliation data through the so-called Research Organization Registry, or ROR (Lammey 2020). This integration of Open Editors with ROR aids in cleaning the data, for a single affiliation can be written in numerous ways. The TU Wien, for instance, could be spelt out as "Technische Universität Wien", or translated to "Vienna University of Technology" or mixed as "TU Vienna, Österreich". Without ROR, searching for all editors that belong to the TU Wien may necessitate dozens of search queries taking into account all possible variants of spelling the university name, with the risk 
of omitting multiple unknowns. ROR allows one to homogenize multiple spellings into a single identifier.

Having outlined the methodical approach, the next section will present some basic information about the data underlying Open Editors' latest round of webscraping.

\section{Results}

\section{Representativeness of the Current Sample}

It is estimated that there exist circa 16,780 scientific publishers globally (according to data based on OpenAlex, cf. Pollock 2022), which is barely possible to be represented in one dataset. However, the current sample includes, inter alia, 15 of the 44 - or almost one third of the large-scale publishers that have more than 100 journals. While this group represents only $0.26 \%$ of all academic publishers, they were responsible for almost two thirds $(65 \%)$ of the total scientific output in 2021 (Pollock 2022). In an admittedly rough estimation, the editors covered by Open Editors can be said to have been involved in at least one third of that share, that is, in circa $21.67 \%$ of the scholarly publication output (for the sake of cautiousness and simplicity, we leave out the eleven additional small- to mid-sized publishers covered by Open Editors). Since OpenAlex itself might inhere omissions of an unknown scale, one may remain on the safe side and estimate that the editors covered by our sample may have processed approximately a fifth of the total scientific output in 2021.

Given the immense heterogeneity of the publishers' and journals' publication patterns, this section will continue with descriptive (rather than inferential) statistics.

\section{Overall Number of Editors}

Open Editors found 594,580 editorial membership positions from 7,352 journals pertaining to 26 publishers, with an average of 81 editors and a median of 34 editors per journal (see Table 2).

Table 2. Summary statistics showing number of editors per journal $(\mathrm{N}=7352)$.

\begin{tabular}{llllllll}
\hline Mean & Median & Mode & Std.Dev. & Minimum & Q1 & Q3 & Maximum \\
\hline 80.9 & 34 & 11 & 467 & 1 & 20 & 53.2 & 13967 \\
\hline
\end{tabular}


The standard deviation of 467 editors indicates that scientific journals are highly heterogeneous in terms of their editorial board sizes; Figure 2 offers a glimpse into the strongly long-tailed distribution, and Figure 3 shows a closer look at all journals with no more than 100 editors (i.e., 6,860 journals, or ca. $93 \%$ of the dataset). It reveals that the modal journal has 11 editorial board members, followed by journals with 22 members, 29 members, 12 members, and 24 members. Most journals exhibit an editorial board size ranging between 10 and 45 editorial board members.

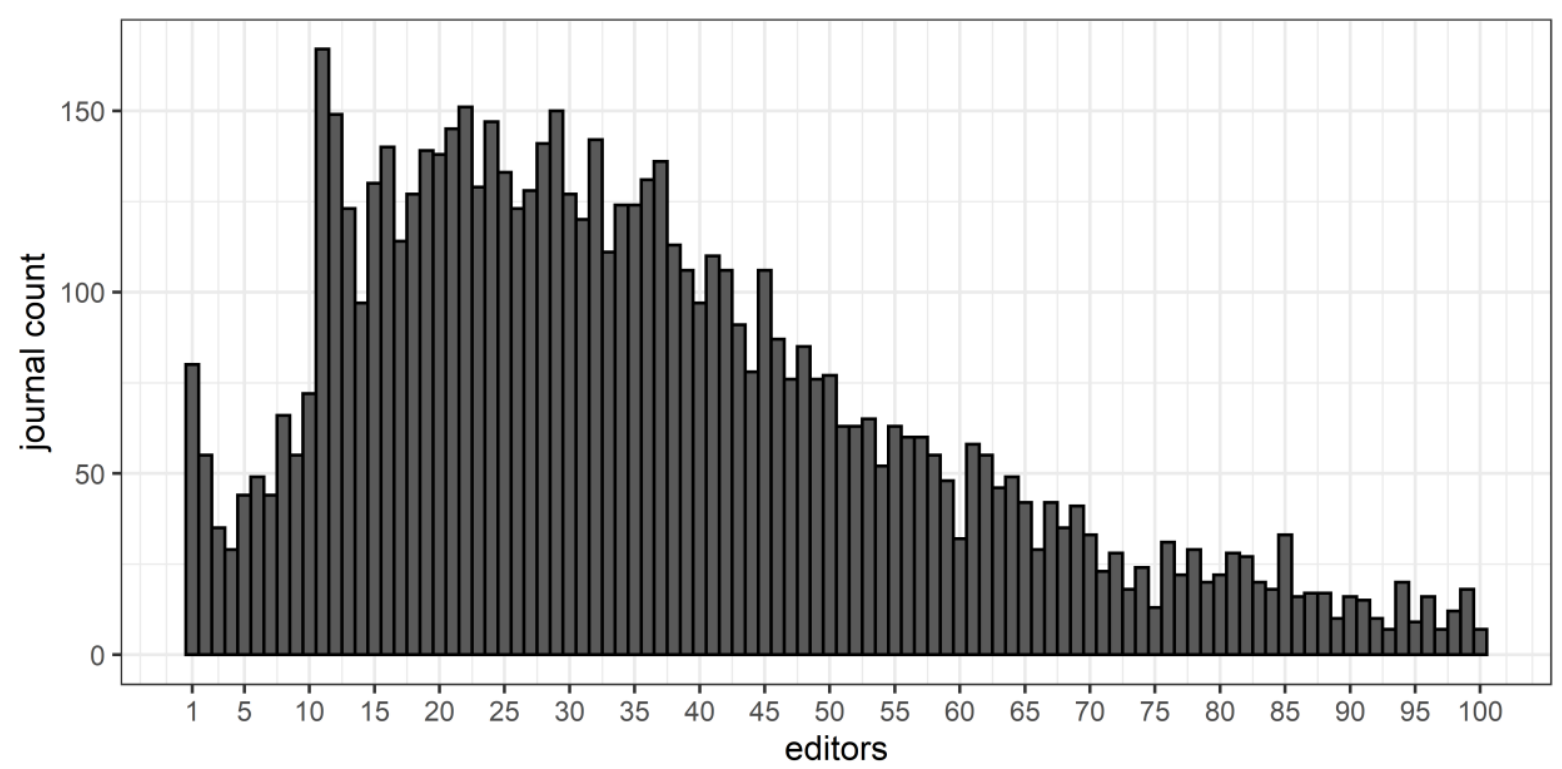

Figure 2. Histogram showing the distribution of the number of editors per journal, based on $99 \%$ of journals in the dataset (the top $1 \%$ of journals, 74 in total, is not shown because their extremely large numbers would skew the graph too strongly). 


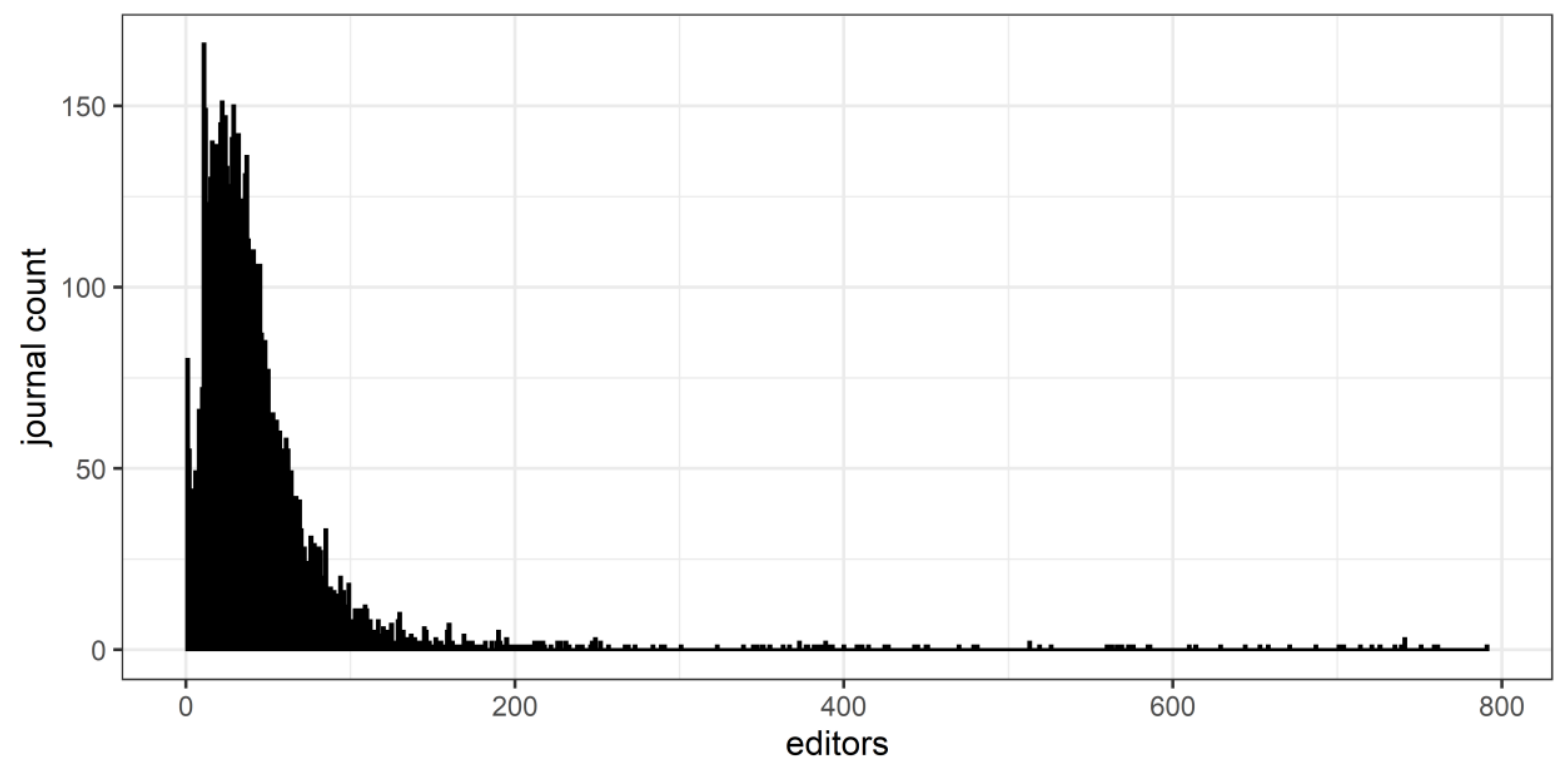

Figure 3. Zoom-in into the head of the histogram in Figure 2, showing the distribution of the number of editors per journal.

There are extreme outliers with regard to the number of editorial board members. Most of these outliers belong to the publisher Frontiers, where the journal with the highest number of editorial board members is Frontiers in Psychology (13,967 individuals). Other than Frontiers outlets, megajournals such as PLoS ONE (9,001 researchers on their board), PeerJ (1,673 editorial board members) and eLife (870 persons) can likewise be found within the far end of the distribution.

\section{Publisher-Level Summary Statistics}

Grouped by publisher, basic descriptive data is visible in Table 3. The number of journals and editors varies quite starkly between the publishers, though most of them have a median count of editors per journal of around 25. There are some conspicuous outliers (mostly unsurprising due to their nature as megajournals), such as PeerJ (Mdn =1,673), eLife (Mdn = 870), Frontiers $(\mathrm{Mdn}=805.5)$, and PLoS $(\mathrm{Mdn}=199.5)$. Not showing these outliers, Figure 4 visualizes the distribution of the numeric composition of editorial boards by publisher. 
Table 3. Basic information about the number of journals and editors by publisher.

\begin{tabular}{|c|c|c|c|c|c|c|c|c|c|c|}
\hline Publisher & Journals & Editors & $\mathbf{M}^{\mathbf{a}}$ & $\mathbf{M d n}^{\mathrm{a}}$ & Mode $^{\mathrm{a}}$ & $\mathbf{S D}^{\mathrm{a}}$ & $\operatorname{Min}^{\mathrm{a}}$ & $\mathbf{Q 1}^{\mathrm{a}}$ & $\mathbf{Q 3}^{\mathbf{a}}$ & $\operatorname{Max}^{\mathbf{a}}$ \\
\hline Allied Academies & 27 & 460 & 17.0 & 12.0 & 19 & 14.6 & 4 & 8.5 & 19.0 & 70 \\
\hline APA & 53 & 3412 & 64.4 & 56.0 & 39 & 31.8 & 19 & 40.0 & 79.0 & 160 \\
\hline ASCE & 16 & 754 & 47.1 & 50.5 & 63 & 16.8 & 16 & 36.5 & 61.5 & 67 \\
\hline BioMedCentral & 216 & 13308 & 61.6 & 50.0 & 28 & 56.6 & 1 & 36.8 & 69.2 & 614 \\
\hline Brill & 314 & 7589 & 24.2 & 22.0 & 20 & 14.0 & 1 & 14.2 & 32.0 & 87 \\
\hline Cambridge UP & 383 & 12485 & 32.6 & 29.0 & 24 & 21.3 & 1 & 19.0 & 42.0 & 173 \\
\hline eLife & 1 & 870 & 870.0 & 870.0 & 870 & NA & 870 & 870.0 & 870.0 & 870 \\
\hline Elsevier & 2347 & 112947 & 48.1 & 41.0 & 36 & 39.5 & 1 & 25.0 & 61.0 & 726 \\
\hline Emerald & 220 & 11565 & 52.6 & 40.5 & 29 & 37.2 & 12 & 30.0 & 61.0 & 252 \\
\hline Frontiers & 134 & 278842 & 2080.9 & 805.5 & 741 & 2688.2 & 1 & 446.5 & 2625.0 & 13967 \\
\hline Hindawi & 240 & 14939 & 62.2 & 25.0 & 16 & 149.5 & 1 & 16.0 & 51.8 & 1719 \\
\hline IGI Global & 228 & 10200 & 44.7 & 42.0 & 37 & 21.6 & 3 & 31.0 & 53.2 & 189 \\
\hline iMedPub & 160 & 3623 & 22.6 & 20.0 & 15 & 15.6 & 4 & 14.0 & 25.0 & 130 \\
\hline Inderscience & 468 & 16535 & 35.3 & 32.0 & 21 & 19.3 & 1 & 22.0 & 43.0 & 190 \\
\hline John Benjamins & 90 & 2549 & 28.3 & 27.0 & 24 & 10.9 & 5 & 22.0 & 33.8 & 61 \\
\hline Karger & 99 & 3502 & 35.4 & 33.0 & 44 & 23.3 & 1 & 17.5 & 48.0 & 129 \\
\hline Longdom & 171 & 6838 & 4.00 & 33.0 & 21 & 31.9 & 8 & 23.0 & 47.0 & 347 \\
\hline MDPI & 376 & 8724 & 23.2 & 14.0 & 11 & 22.6 & 10 & 12.0 & 24.0 & 215 \\
\hline PeerJ & 1 & 1673 & 1673.0 & 1673.0 & 1673 & NA & 1673 & 1673.0 & 1673.0 & 1673 \\
\hline Pleiades & 115 & 3182 & 27.7 & 26.0 & 20 & 9.5 & 10 & 21.0 & 32.0 & 58 \\
\hline PLOS & 12 & 11059 & 921.6 & 199.5 & 39 & 2547.6 & 39 & 101.5 & 244.8 & 9001 \\
\hline $\mathrm{RSC}$ & 42 & 2932 & 69.8 & 65.0 & 54 & 32.3 & 12 & 50.2 & 86.2 & 193 \\
\hline SAGE & 1195 & 57859 & 48.4 & 38.0 & 37 & 38.5 & 1 & 26.0 & 60.0 & 481 \\
\hline SCIRP & 247 & 6145 & 24.9 & 23.0 & 23 & 9.6 & 5 & 18.0 & 30.5 & 58 \\
\hline SciTechnol & 81 & 1280 & 15.8 & 15.0 & 15 & 7 & 1 & 12.0 & 20.0 & 39 \\
\hline Springer Nature & 116 & 1308 & 11.3 & 6.0 & 2 & 13.4 & 1 & 3.0 & 12.2 & 68 \\
\hline
\end{tabular}

${ }^{\mathrm{a}}$ Journals per Editor 


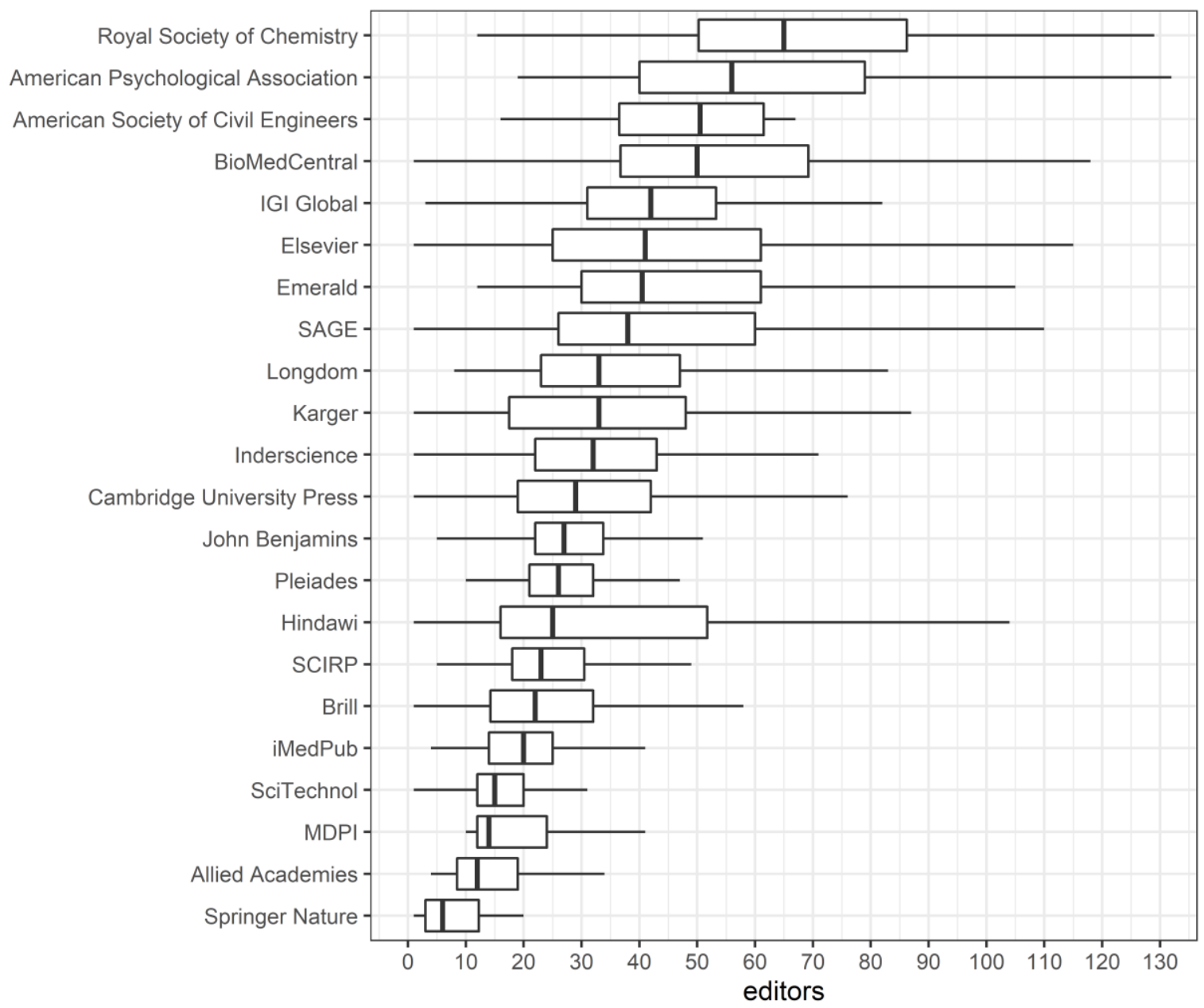

Figure 4. Boxplots showing the distribution of the number of editors per journal grouped by publishers (outliers are blended out; and the publishers eLife, Frontiers, PeerJ, and PLoS are likewise missing because their inclusion would distort the visualisation too strongly).

\section{Editorial Roles and Diversity}

Not all editorial board members are of equal weight. Instead, some roles typically convey greater responsibility and a more intense workload than others. The dataset contains various labels and spellings with regard to these editorial positions. It found 4,024 distinct names for the respective roles of the editors, the most common ones being 'Review Editor', 'Editorial Board', and 'Guest Associate Editor'. Some less frequent attributes are 'Post-doctoral Board', 'Media Review Editors', 'International Consultant Editors' and 'Editorial Board Assistant'. With thousands of different titles, it seems difficult to generate a manageable typology of the various journal positions that researchers occupy with their editorial tasks. 
Some publishers, however, seem to have taxonomized the labels of editorial tasks across their journal portfolio. The publisher Frontiers offers an example, as it only uses nine distinctly labelled roles for the almost 280,000 editorial board members across 92 journals (Table 4).

Table 4. Editorial roles and their frequency at the journals of the publisher Frontiers, offering an example of standardized editorial role labels.

\begin{tabular}{lrr}
\hline Role & Frequency & Share (in \%) \\
\hline Review Editor & 162627 & 58.322 \\
Guest Associate Editor & 77608 & 27.832 \\
Associate Editor & 36909 & 13.237 \\
Specialty Chief Editor & 1455 & 0.522 \\
Field Chief Editor & 125 & 0.045 \\
Reviewer & 73 & 0.026 \\
Assistant Specialty Chief Editor & 23 & 0.008 \\
Editor-in-Chief & 8 & 0.003 \\
Chief Editor & 5 & 0.002 \\
Managing Editor & 4 & 0.001 \\
Assistant Field Chief Editor & 3 & 0.001 \\
Assistant Chief Editor & 2 & 0.001 \\
\hline
\end{tabular}

\section{Geographical Distribution}

The researchers' affiliations often disclose the countries that harbour their respective institution. Using the 'world cities'-dataset from the R library 'maps' (Becker et al. 2018), one can count the frequency with which each country is mentioned. In total, a superficial analysis finds 194 countries and territories listed across ca. $94.3 \%$ of all editorial board positions, with the remaining $5.7 \%$ not disclosing any country names.

At the continent-level, Europe occupies over a third (35.7\%) of the editorial positions; North America more than a fourth (27.5\%); and Asia more than a fifth (20.4\%). Latin America and Oceania have a share of roughly $4 \%$ each, while African affiliations are visible in only $1.5 \%$ 
of the editorial board positions in the present dataset. Juxtaposing them with the global population as taken from the World Bank would suggest large discrepancies between editorial representation and global population share. Figure 5 visualizes that lack of correlation, with the left bars showing the editorial representation, and the right ones showing the world population share.

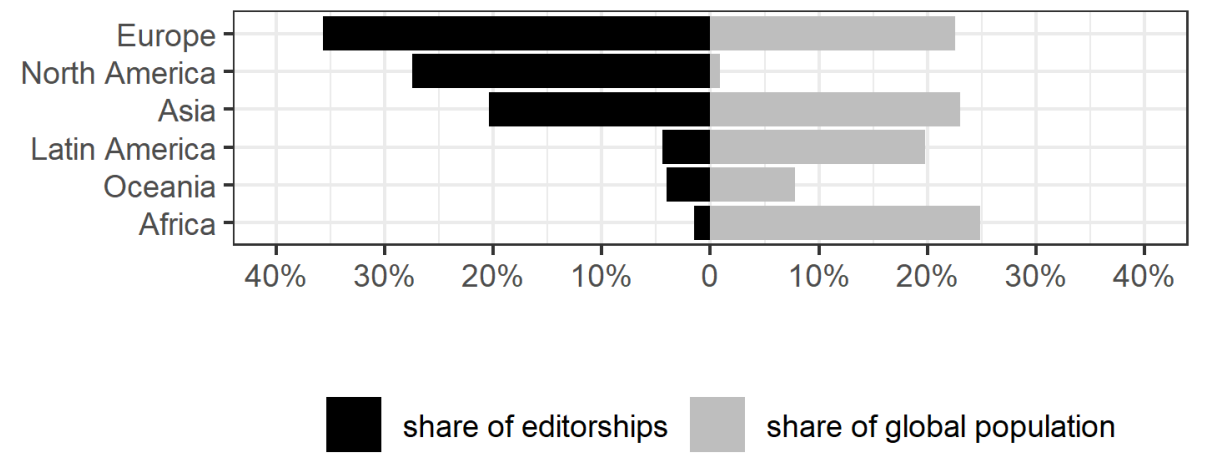

Figure 5. The most frequently mentioned continents in the editors' affiliations (left bars, black) juxtaposed with the share of world population (right bars, grey).

Unsurprisingly, therefore, even on the country-level rather than continent-level there is no statistically significant correlation between representation in the editorial boards of scientific journals and population size, according to a Kendall's tau test $\left(r_{\tau}=0.4, p>0.05\right)$.

Speaking of which, treading from the continent-level to country-level data leads to the aggregation in Figure 6. It offers a view of the 30 most frequently mentioned countries (see the bars on the left-hand side). The U.S. leads the ranking, occupying more than a fourth of all editorial board positions in the dataset. China comes second with slightly less than $10 \%$, followed by the U.K. in the third position. Italy, Germany, Australia, Canada, Spain, France, and India round up the top ten of the most frequently mentioned affiliation-countries.

To put these numbers into a perspective beyond world population counts, the right-hand bars in Figure demonstrate the respective countries' total scientific outputs (according to the numbers taken from Scimago Journal \& Country Rank 2022). Not only is there a graphical symmetry visible; there is also indeed a strong positive correlation between a country's total scientific output and their numerical representation in the editorial boards covered by Open Editors, $r_{\tau}=0.7, p<.01$. 


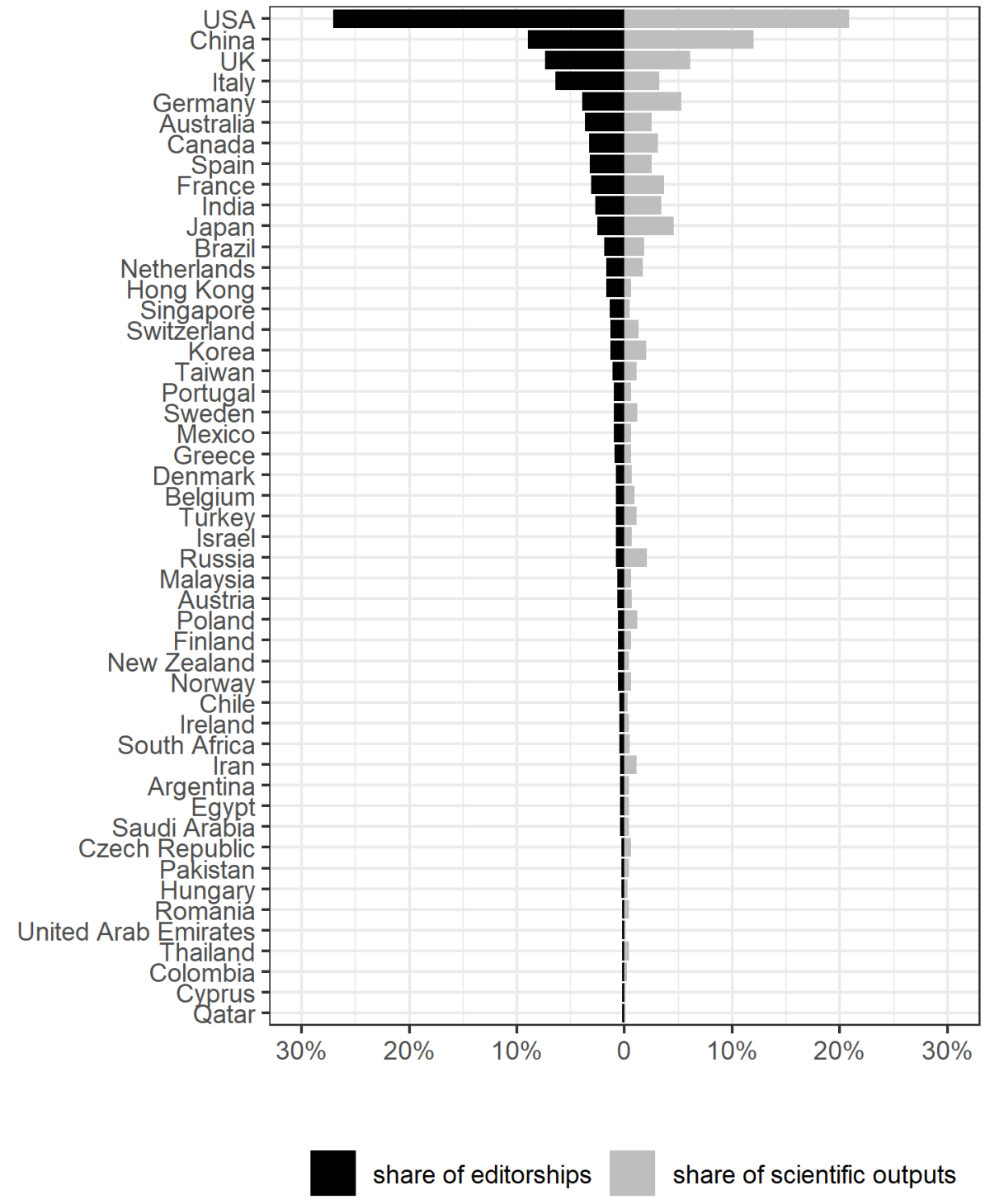

Figure 6. Most frequently mentioned countries in the affiliations of the Open Editors dataset, juxtaposed with the respective country's share of total scientific outputs in 2021.

One could also look at the frequency of countries listed in the affiliations of those researchers who (allegedly) serve in the boards of predatory journals. The present paper can only offer a superficial glimpse to illustrate the dataset's utility, but the list of the ten countries most present at the five predatory publishers covered by the dataset (Allied Academies, iMedPub, Longdom, SCIRP, and SciTechnol) indicates that some countries such as Turkey and Egypt are overrepresented at predatory journals when compared to their presence at all the other publishers (see Figure 7, with the left bars indicating the share of editorships at non-predatory, and the right bars indicating the share of editorships at predatory outlets). But with the U.S. 
leading that enumeration, and with countries like Italy, Canada, UK, Japan, and Spain included in the top ten list as well, the graph indicates that the issue of predatory publishers is not a problem merely of the 'Global South', but also an acute concern for research culture in Europe and North America as well.

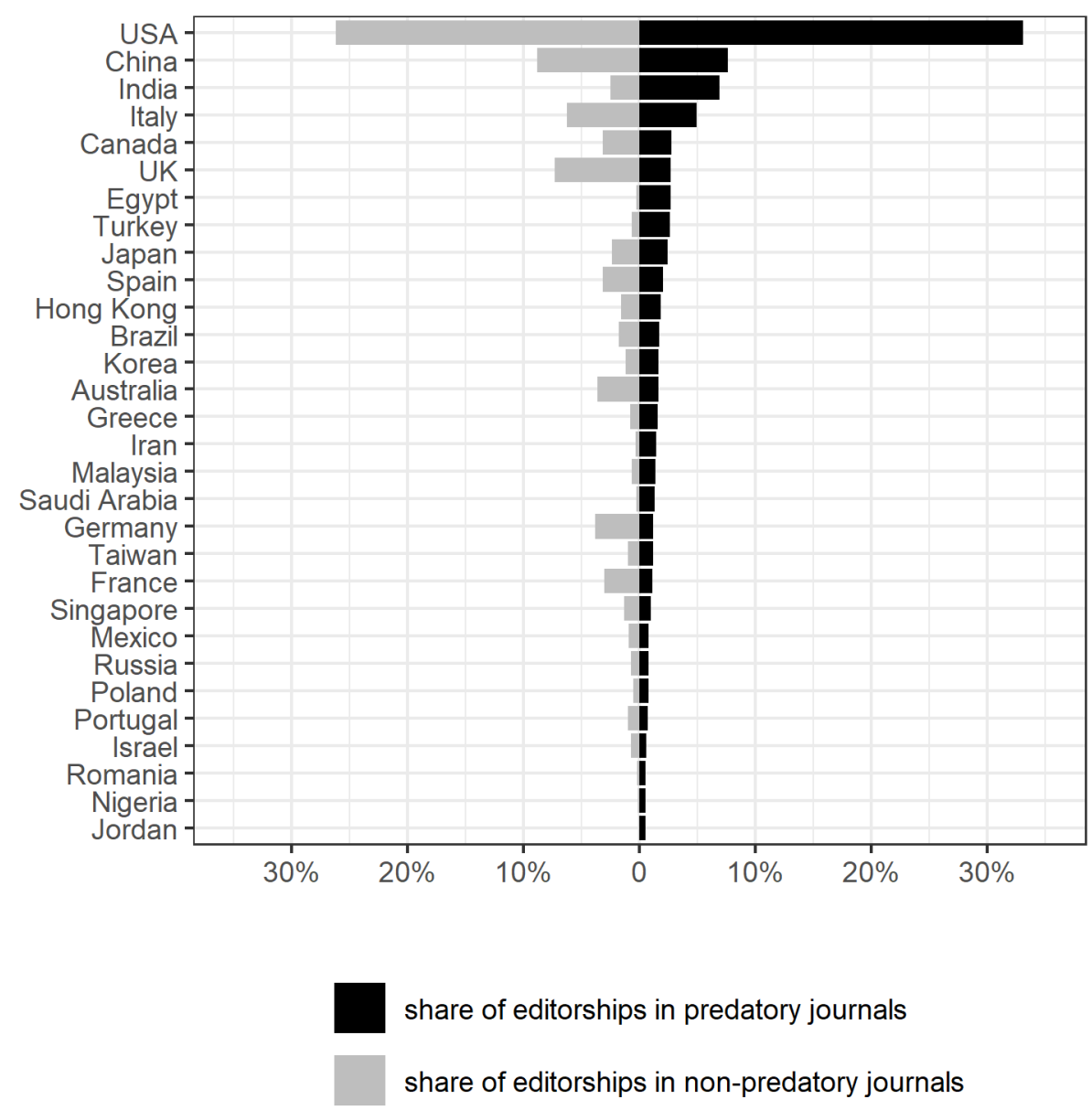

Figure 7. Most frequently mentioned countries in the affiliations of the editors at the five predatory publishers Allied Academies, iMedPub, Longdom, SCIRP and SciTechnol, compared with their representation in nonpredatory outlets.

Indeed, the geographical representation in the dataset's predatory and the non-predatory publishers correlates strongly, with Kendall's tau $r_{\tau}=0.95, p<0.01$.

Looking at the geographical diversity at the journal-level, one can again see how heterogeneous the scholarly publication system is. Grouped by publisher, Frontiers' median journal exhibits the largest number of distinct countries (almost 60), followed by the megajournals PeerJ (46), 
eLife (41), and the median PLoS journal (24.5), cf. Figure 8. Across all journals and publishers, the median number of distinct countries represented in an editorial board is eleven.

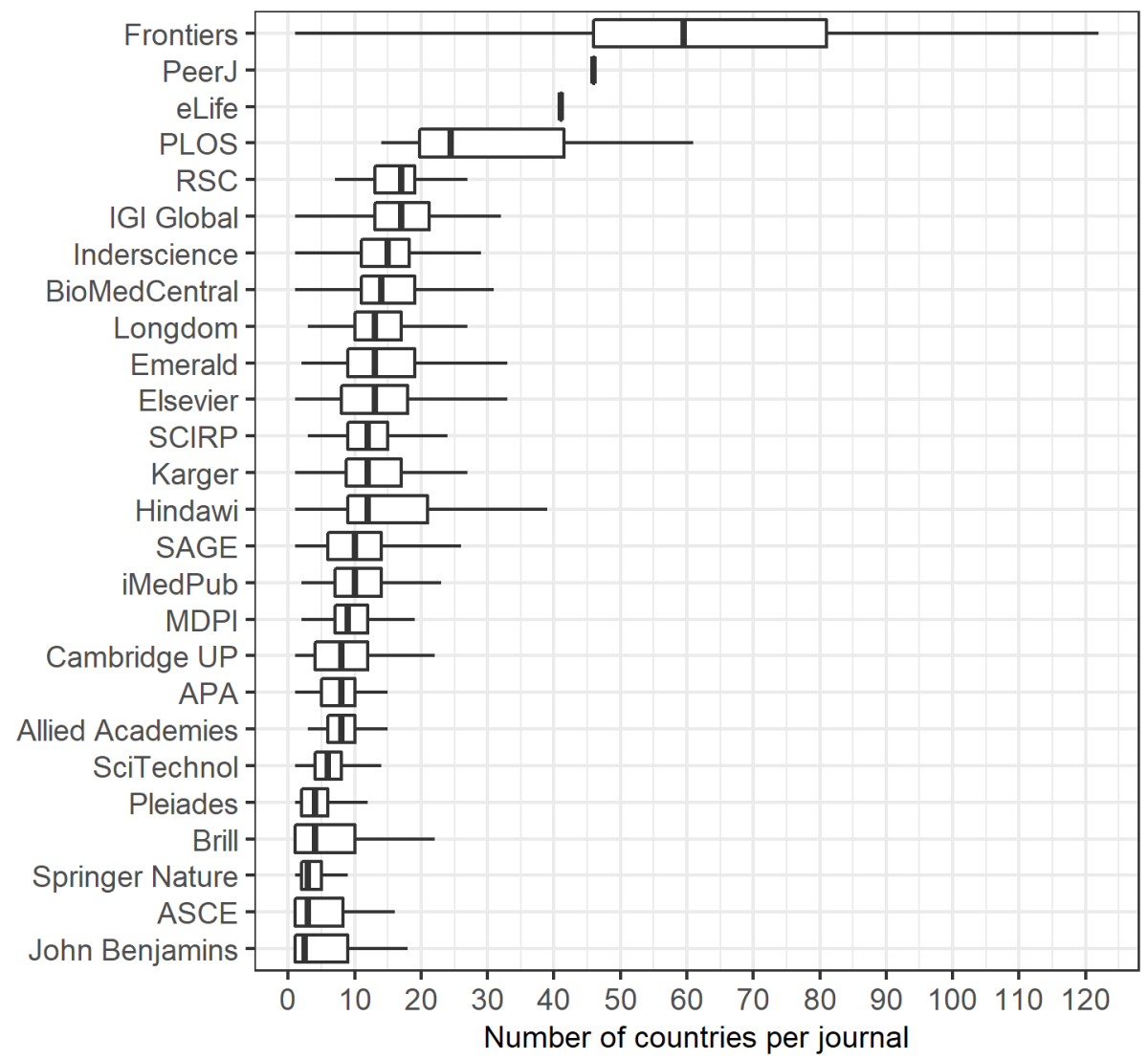

Figure 8. Boxplot showing the distribution of the number of affiliation-countries represented in the editorial boards of journals, grouped by publisher.

To give a closer illustration, Table 5 enumerates the top five countries listed in every journal grouped by publisher (discounting missing values). The U.S. dominates most of the publishers' editorial boards, or 22 out of 26, and it is always among the top five represented countries. China is listed in 20 of these enumerations, the U.K. in 18, and Italy in 14. 
Table 5. The five most-frequently mentioned countries in the affiliations of the journals' editorial boards, grouped by publisher.

\begin{tabular}{|c|c|c|c|c|c|}
\hline Publisher & $\# 1$ & $\# 2$ & $\# \mathbf{3}$ & $\# 4$ & $\# 5$ \\
\hline Allied Academies & $\begin{array}{l}\text { India } \\
71(15.9 \%)\end{array}$ & $\begin{array}{c}\text { USA } \\
69(15.5 \%)\end{array}$ & $\begin{array}{c}\text { Italy } \\
44(9.9 \%)\end{array}$ & $\begin{array}{c}\text { China } \\
21(4.7 \%)\end{array}$ & $\begin{array}{c}\text { Egypt } \\
20(4.5 \%)\end{array}$ \\
\hline APA & $\begin{array}{c}\text { USA } \\
2450(73.3 \%)\end{array}$ & $\begin{array}{c}\text { Canada } \\
228(6.8 \%)\end{array}$ & $\begin{array}{c}\text { UK } \\
121(3.6 \%)\end{array}$ & $\begin{array}{l}\text { Australia } \\
84(2.5 \%)\end{array}$ & $\begin{array}{l}\text { Germany } \\
78(2.3 \%)\end{array}$ \\
\hline ASCE & $\begin{array}{c}\text { Australia } \\
11(11.7 \%)\end{array}$ & $\begin{array}{c}\text { China } \\
11(11.7 \%)\end{array}$ & $\begin{array}{l}\text { Hong Kong } \\
10(10.6 \%)\end{array}$ & $\begin{array}{l}\text { Taiwan } \\
6(6.4 \%)\end{array}$ & $\begin{array}{c}\text { USA } \\
6(6.4 \%)\end{array}$ \\
\hline BioMedCentral & $\begin{array}{c}\text { USA } \\
3530(25.4 \%)\end{array}$ & $\begin{array}{c}\text { UK } \\
1135(8.2 \%)\end{array}$ & $\begin{array}{c}\text { China } \\
1029(7.4 \%)\end{array}$ & $\begin{array}{l}\text { Australia } \\
743(5.4 \%)\end{array}$ & $\begin{array}{c}\text { Italy } \\
727(5.2 \%)\end{array}$ \\
\hline Brill & $\begin{array}{c}\text { USA } \\
572(22.3 \%)\end{array}$ & $\begin{array}{c}\text { UK } \\
206(8 \%)\end{array}$ & $\begin{array}{c}\text { China } \\
168(6.5 \%)\end{array}$ & $\begin{array}{l}\text { Germany } \\
150(5.8 \%)\end{array}$ & $\begin{array}{l}\text { Hong Kong } \\
126(4.9 \%)\end{array}$ \\
\hline Cambridge UP & $\begin{array}{c}\text { USA } \\
4536(37.5 \%)\end{array}$ & $\begin{array}{c}\text { UK } \\
2182(18 \%)\end{array}$ & $\begin{array}{c}\text { Canada } \\
678(5.6 \%)\end{array}$ & $\begin{array}{l}\text { Australia } \\
677(5.6 \%)\end{array}$ & $\begin{array}{c}\text { Germany } \\
375(3.1 \%)\end{array}$ \\
\hline eLife & $\begin{array}{c}\text { USA } \\
434(51.2 \%)\end{array}$ & $\begin{array}{c}\text { UK } \\
61(7.2 \%)\end{array}$ & $\begin{array}{l}\text { Germany } \\
41(4.8 \%)\end{array}$ & $\begin{array}{c}\text { China } \\
33(3.9 \%)\end{array}$ & $\begin{array}{c}\text { Canada } \\
29(3.4 \%)\end{array}$ \\
\hline Elsevier & $\begin{array}{c}\text { USA } \\
35191(30.2 \%)\end{array}$ & $\begin{array}{c}\text { China } \\
9658(8.3 \%)\end{array}$ & $\begin{array}{c}\text { UK } \\
8676(7.4 \%)\end{array}$ & $\begin{array}{c}\text { France } \\
4770(4.1 \%)\end{array}$ & $\begin{array}{c}\text { Australia } \\
4652(4 \%)\end{array}$ \\
\hline Emerald & $\begin{array}{c}\text { USA } \\
2367(19.8 \%)\end{array}$ & $\begin{array}{c}\text { UK } \\
2236(18.7 \%)\end{array}$ & $\begin{array}{c}\text { Australia } \\
901(7.5 \%)\end{array}$ & $\begin{array}{l}\text { China } \\
714(6 \%)\end{array}$ & $\begin{array}{c}\text { Canada } \\
344(2.9 \%)\end{array}$ \\
\hline Frontiers & $\begin{array}{c}\text { USA } \\
66554(21.9 \%)\end{array}$ & $\begin{array}{c}\text { China } \\
34276(11.3 \%)\end{array}$ & $\begin{array}{c}\text { Italy } \\
24390(8 \%)\end{array}$ & $\begin{array}{c}\text { UK } \\
17424(5.7 \%)\end{array}$ & $\begin{array}{c}\text { Germany } \\
13223(4.4 \%)\end{array}$ \\
\hline Hindawi & $\begin{array}{c}\text { Italy } \\
2775(17.2 \%)\end{array}$ & $\begin{array}{c}\text { USA } \\
2415(15 \%)\end{array}$ & $\begin{array}{c}\text { China } \\
1652(10.2 \%)\end{array}$ & $\begin{array}{c}\text { Spain } \\
803(5 \%)\end{array}$ & $\begin{array}{c}\text { Japan } \\
689(4.3 \%)\end{array}$ \\
\hline IGI Global & $\begin{array}{c}\text { USA } \\
2364(21.4 \%)\end{array}$ & $\begin{array}{c}\text { India } \\
1179(10.7 \%)\end{array}$ & $\begin{array}{c}\text { UK } \\
658(6 \%)\end{array}$ & $\begin{array}{c}\text { China } \\
527(4.8 \%)\end{array}$ & $\begin{array}{c}\text { Italy } \\
385(3.5 \%)\end{array}$ \\
\hline iMedPub & $\begin{array}{c}\text { USA } \\
725(21.1 \%)\end{array}$ & $\begin{array}{c}\text { India } \\
453(13.2 \%)\end{array}$ & $\begin{array}{c}\text { China } \\
211(6.2 \%)\end{array}$ & $\begin{array}{c}\text { Italy } \\
186(5.4 \%)\end{array}$ & $\begin{array}{c}\text { Turkey } \\
168(4.9 \%)\end{array}$ \\
\hline Inderscience & $\begin{array}{c}\text { USA } \\
4029(22.3 \%)\end{array}$ & $\begin{array}{c}\text { UK } \\
1514(8.4 \%)\end{array}$ & $\begin{array}{c}\text { China } \\
1295(7.2 \%)\end{array}$ & $\begin{array}{c}\text { India } \\
832(4.6 \%)\end{array}$ & $\begin{array}{c}\text { Italy } \\
782(4.3 \%)\end{array}$ \\
\hline John Benjamins & $\begin{array}{c}\text { USA } \\
140(17.2 \%)\end{array}$ & $\begin{array}{c}\text { UK } \\
92(11.3 \%)\end{array}$ & $\begin{array}{c}\text { Hong Kong } \\
56(6.9 \%)\end{array}$ & $\begin{array}{c}\text { China } \\
38(4.7 \%)\end{array}$ & $\begin{array}{c}\text { France } \\
36(4.4 \%)\end{array}$ \\
\hline Karger & $\begin{array}{c}\text { USA } \\
775(22.2 \%)\end{array}$ & $\begin{array}{c}\text { Germany } \\
479(13.7 \%)\end{array}$ & $\begin{array}{c}\text { Japan } \\
234(6.7 \%)\end{array}$ & $\begin{array}{c}\text { Italy } \\
230(6.6 \%)\end{array}$ & $\begin{array}{c}\text { UK } \\
175(5 \%)\end{array}$ \\
\hline Longdom & $\begin{array}{c}\text { USA } \\
2864(42 \%)\end{array}$ & $\begin{array}{c}\text { India } \\
391(5.7 \%)\end{array}$ & $\begin{array}{c}\text { China } \\
357(5.2 \%)\end{array}$ & $\begin{array}{c}\text { Italy } \\
314(4.6 \%)\end{array}$ & $\begin{array}{c}\text { Japan } \\
216(3.2 \%)\end{array}$ \\
\hline MDPI & $\begin{array}{c}\text { USA } \\
1844(20.1 \%)\end{array}$ & $\begin{array}{c}\text { Italy } \\
1641(17.9 \%)\end{array}$ & $\begin{array}{c}\text { Spain } \\
731(8 \%)\end{array}$ & $\begin{array}{c}\text { UK } \\
616(6.7 \%)\end{array}$ & $\begin{array}{c}\text { France } \\
444(4.8 \%)\end{array}$ \\
\hline PeerJ & $\begin{array}{c}\text { USA } \\
25(15.8 \%)\end{array}$ & $\begin{array}{l}\text { Australia } \\
12(7.6 \%)\end{array}$ & $\begin{array}{c}\text { Hong Kong } \\
10(6.3 \%)\end{array}$ & $\begin{array}{c}\text { China } \\
9(5.7 \%)\end{array}$ & $\begin{array}{c}\text { Italy } \\
9(5.7 \%)\end{array}$ \\
\hline
\end{tabular}




\begin{tabular}{lccccc} 
Pleiades & Russia & USA & Germany & Belarus & France \\
& $2310(79.1 \%)$ & $130(4.5 \%)$ & $60(2.1 \%)$ & $45(1.5 \%)$ & $44(1.5 \%)$ \\
PLOS & USA & UK & Australia & India & China \\
& $950(33.1 \%)$ & $228(7.9 \%)$ & $132(4.6 \%)$ & $112(3.9 \%)$ & $110(3.8 \%)$ \\
RSC & USA & China & UK - 292 & Germany & Japan \\
& $634(24.2 \%)$ & $408(15.6 \%)$ & $(11.1 \%)$ & $150(5.7 \%)$ & $113(4.3 \%)$ \\
SAGE & USA & UK & Australia & Canada & India \\
& $2559(44.8 \%)$ & $6972(12.2 \%)$ & $2746(4.8 \%)$ & $2481(4.3 \%)$ & $1615(2.8 \%)$ \\
SCIRP & USA & China & India & Italy & Canada \\
& $1908(29 \%)$ & $768(11.7 \%)$ & $331(5 \%)$ & $314(4.8 \%)$ & $227(3.5 \%)$ \\
SciTechnol & USA & UK & Canada & Italy & China \\
& $532(47.1 \%)$ & $64(5.7 \%)$ & $50(4.4 \%)$ & $46(4.1 \%)$ & $40(3.5 \%)$ \\
Springer Nature & USA & UK & Germany & Italy & China \\
& $90(17.3 \%)$ & $88(17 \%)$ & $39(7.5 \%)$ & $34(6.6 \%)$ & $30(5.8 \%)$ \\
\hline
\end{tabular}

\section{Share of Anglo-American Affiliations}

With Australia and Canada likewise present in many of these top five-lists, one may explore the extent to which the scientific publication system exhibits an Anglo-American dominance (based on the sum of editorial board affiliations located in the U.S., U.K., Canada, Australia, and New Zealand). In Figure 9, one can see that there are some publishers where at least half the editorial teams are based at Anglo-American institutes. That list is led by the journals of the APA with a median Anglo-American share of $90.3 \%$, followed by Cambridge University Press with $72.7 \%$, SAGE with $70.7 \%$, eLife with $64.5 \%$, the predatory publisher SciTechnol with 59.6\%, PLoS with 58,85\%, Emerald with 51.75\%, and Springer Nature with 50\% (the percentages discount those affiliations where no country name could be extracted automatically) 


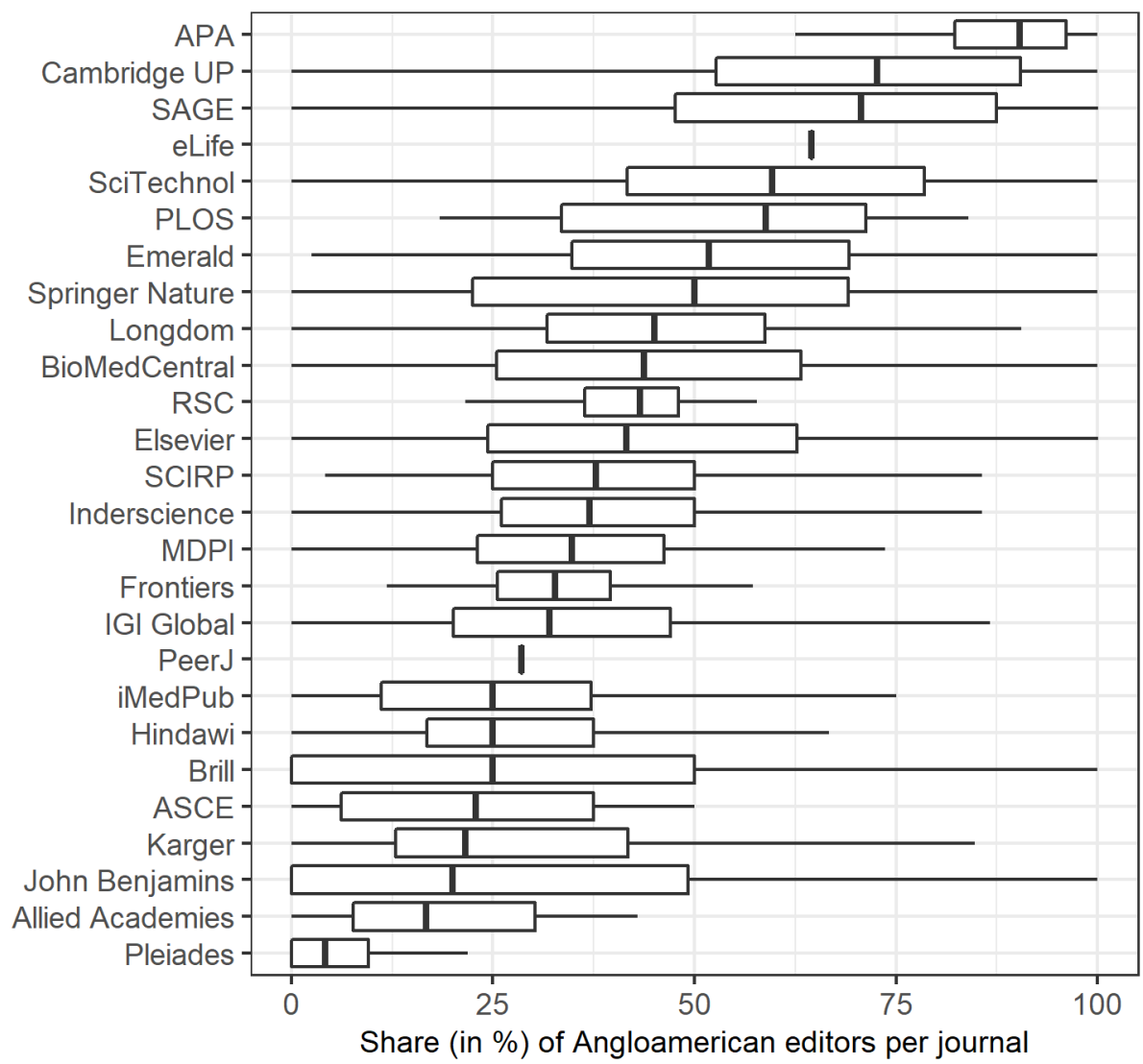

Figure 9. The distribution of the Anglo-American shares in the affiliation-countries represented in the editorial boards of journals, grouped by publisher.

All in all, the summary statistics presented in this section point to a highly heterogeneous landscape of journals and their editorial boards, of publishers and their regional diversity, of editorial roles and labels. The descriptive data merely offer some superficial glances, but they thereby illustrate the analytical utility of the dataset for further research and practice.

\section{Implications on Dataset Usage and Measuring Diversity}

\section{Four Use Cases to Further Utilize the Dataset}

Open Editors scraped the websites of thousands of academic journals to collect and structure data about half a million editorial positions, making them available under a CC0 license for anyone to use and analyse, with a pledge to keep the data up to date by iterating the scraping on a regular basis. With this large-scale dataset, the conduct of editormetric analyses should 
become more efficient, more effortless, and more reproducible. Possible investigations that could draw from this dataset include analyses regarding the gender composition of editorial boards; the regional diversity among editors; the possibility to detect the frequency to which editors publish in their own journals; the representation of early career researchers in the landscape of scholarly publications; the degree to which inter-disciplinary publishing is realized; and other issues pertinent to research evaluation and research assessment.

Four (semi-)fictitious examples may illustrate the utility of the dataset for both researchers and for practitioners (such as university librarians and research evaluators), examples that are partly in line with recent calls to '[r]ecognize the diversity of research activities and practices, with a diversity of outputs, and [... to] valorize the diversity in research roles and careers' (European Commission 2021 p. 12).

First, say that the Ministry of Science in the Czech Republic initiates an awareness-raising campaign regarding predatory publishers. Before doing so, however, they wish to explore the presence of Czech-affiliated scholars across predatory journals. Using Open Editors, the Ministry could filter the dataset for the five predatory publishers contained therein and query it in conjunction with the country name. Using the web version of Open Editors, a possible query could perhaps be ("Allied Academies" OR iMedPub OR Longdom OR SCIRP OR SciTechnol) AND (Czech OR Czechia OR Brno OR Prague OR Prag OR Praha OR Ostrava OR Olomouc), which leads to 40 supposedly Czech-affiliated researchers. In a further step, the Ministry could verify the identity of these 40 persons listed at the predatory journals and warn them about the nature of the journals that boast their names (Downes 2020).

A second fictitious use case may relate to a small university library's need to assess the presence of their institute's scholars across a certain publisher's editorial boards (e.g., Karger) because negotiations about a renewal of an institutional subscription of their journals are imminent. Imagine that the university's scholars hardly publish in Karger journals, which suggests that perhaps a renewal of the subscription might be dispensable, or only expedient if the publisher's proposed price was lower than before. Using data from Open Editors, the university's research evaluators could have an additional source at hand, either to corroborate the library's argument for a lower price, or to offer a counterargument if it turns out that the institution's scholars actually occupy active editorial positions at Karger journals. Whatever the outcome of this editormetric analysis, tapping the dataset will always offer a richer view of 
an institute's linkages to a given publisher, thus providing crucial data to support negotiations between libraries and publishers with further evidence.

A third example of how the dataset could be (and has already been) practically used would involve research administrators organizing a workshop on scholarly publication ethics. Using Open Editors, they could find out which local researchers serve in journals' editorial boards so as to invite them to that workshop and target them for possible discussions. The participants could be further categorized into various groups depending on whether they serve as chief editors or section editors, as managing editors, or as editorial board members who are merely tasked with reviewing submissions. Other disaggregations could be based on whether the journals they serve on are particularly innovative with regards to Open Science practices (e.g., by publishing Registered Reports or by supporting Open Peer Reviews). Such approaches add greater nuances to the evaluation of academic community services.

Fourth, scientometric research could tap data from Open Editors for various basic scientific purposes. For instance, one study already used this dataset to discover, inter alia, that journallevel open access policies do not necessarily correlate with greater diversity of editorial leadership (Altman \& Cohen 2021). Editormetric research has so far explored many other issues, albeit with a smaller sample size than Open Editors could deliver - such as the extent to which journals exhibit interdisciplinary editorial boards (Wu et al. 2020; Zhang et al. 2021). As many emerging research fields are of an inter- and trans-disciplinary nature, the overrepresentation of a specific discipline's researchers in an editorial board may turn out to be problematic for a journal. Research published in that respective outlet might then not represent the discipline's broader research achievements properly. Relatedly, the dataset could be used to detect the geographical diversity of editorial board compositions (Harzing \& Metz 2013; Mazov \& Gureev 2016). There is evidence that case studies and research with cohorts from only one (so-called "non-Western") country often have difficulties to find acceptance from traditional journals (Wilson \& Knutsen online first), as editorial boards fear such kind of research may not be representative for their readership. If a journal wishes to publish research with regional diversity, then an editorial board with members from different countries might help in attracting submissions with a greater geographical scope. Open Editors may aid in rendering such regional biases visible. A final example of a basic scientometric analysis drawing from the present dataset would be to analyse a given journal's innovativeness in 
correlation with the diversity of the 'academic age' of the editorial board members (Nicholas et al. 2020). As innovative research or emerging topics might find difficulty in getting published in long-standing high impact journals in specific fields (Petersen 2017), this can affect early career researchers with their emerging approaches more often than senior ones. More diverse boards that include early career researchers might smoothen the danger of a traditional topical and methodological bias. Moreover, including more early career researchers as editorial board members, and thus indirectly as reviewers, might help to manage the ever increasing amount of manuscripts submitted to scientific journals, and to shorten the review process (Nguyen et al. 2015). While the present dataset alone does not allow such analyses due to the lack of metadata about the 'academic age' of each person in the editorial board, one could link the dataset to ORCID (Haak et al. 2012), or the Open Researcher and Contributor $I D$, in order to do conduct such investigations, such as by fetching data about the year of graduation as saved in ORCID's metadata.

\section{Dataset Limitations}

Speaking of which, the status quo of the dataset is certainly not yet perfect as such. Instead, Open Editors would enable more elaborate examinations if it was linked with other datasets, especially via PIDs. ORCID would allow one to disambiguate researchers who carry the same names at least in their Latin transcriptions (e.g., "Anna Smith", "Wang Li”), and it would also open a path towards the potentially rich metadata associated with ORCID profiles, such as on individual scholars' peer review activities. An analysis that draws from both Open Editors and ORCID could examine the referees' increased workload that accompanies an editorial position. Or, if ORCID profiles show former institutional affiliations of editors, one could detect the extent to which editors allow researchers from their former organizations to publish in their journals. The addition of persistent identifiers would thus greatly facilitate the task of comprehensive searches and complex analyses based on trustworthy data.

Another limiting issue of the dataset is the underlying data sample. The current approach is based on a necessarily incomplete coverage. While the total number of academic publishers and scholarly journals can only be estimated (Pacher 2021, Johnson et al., 2018), we showed that the editors covered by the dataset may be said to have processed a fifth of the total scientific output in 2021. One should thus keep in mind that the sample remains fragmentary because the 
journals' heterogeneous way of displaying data about editors inhibits a simple webscraping approach. Major examples outside of Open Editors' sample include Oxford University Press, Taylor \& Francis, and Wiley. Nevertheless, even though it may be impossible to get any statistically decent sample given the unknown population, it seems better to collect any available data rather than to discourage related efforts.

The best solution against this issue of the dataset's sample size would be to have a centralized infrastructure that would demand the opening up of uniformly structured editorial data in a topdown manner across every single publisher. Barring such an implementation, another mitigation could be to use webscraping with a default structures of editorial data display by accepting the risk of omitting a large number of journals whose website structure deviate from the default's one (as was done by Philipp Zumstein and Jan Kamlah with regards to Springer and Wiley; cf. Kamlah \& Zumstein 2021)integrate a machine learning approach that would be capable of reading the data about editors regardless of the specific HTML and CSS arrangements (Safder et al. 2020).

As long as this is not achieved, Open Editors provides a sufficient solution: the data are incomplete, the sample's underlying population is unknown, the dataset may be biased towards well-structured publishers. However, once these limitations are accounted for, the dataset is useful in generating some insights for research assessments (e.g., on the presence of an institute's scholars in the editorial boards of serious and predatory journals), in coming up with hypotheses (e.g., on the gendered patterns in chemistry journals versus sociology journals), and in pointing to further avenues for research and practice (e.g., for taxonomizing editorial board roles, or for harmonizing the data display of editorial boards).

\section{Critical Thoughts on Measuring Diversity}

A final aspect we wish to discuss pertains to the potential investigations of social diversity issues that might or might not be possible with the dataset thus accrued. Many editormetric analyses aim to detect biases and inequalities that are sustained by editorial power within the scientific publication system. In doing so, however, they are dependent on the available metadata which, as of now, are largely confined to the editors' names, affiliated institutions, and roles. Such data, especially if they find linkage to PIDs, can be harnessed to illuminate supposedly objective scientometric patterns such as the ones mentioned above - regional 
diversity, interdisciplinarity, or the presence of early career researchers based on a given person's 'academic age'. But to obtain an even broader, overall picture on the state of a less 'objective' and more social constructivist conceptualization of diversity among editorial boards, more information would be needed - but what information?

Some readers might ask why diversity and not merit is the crucial construct in this work. The answer is simple: In an ideal world the two should be equivalent, but in fact they are not. If we have a look at today's academia it is still dominated by a white, cis-male gaze. Many senior researchers and editors owe their positions not only to their hard work, but also to their privileges, while people from (multi-)marginalized groups have a harder time getting there. People affected by classism, racism, ableism, and other forms of discrimination are less likely to gain access to higher education, become a researcher, and reach tenure or editor positions regardless of their competence. This is not because they are less skilled, but because on top of their work they have to tackle individual, institutional, and structural discrimination. Due to homophily and other effects this bias continues, e.g., editors are more likely to choose research to be published which fits their perspectives and to invite co-editors that think alike. Open Editors as a measurement for diversity might become a useful indicator for (lacking) diversity of editorial boards and a reminder for change, for example if combined with quotas.

However, diversity refers to a multitude of variables that intersect and go beyond region of origin. This is where dilemmas arise, as this category of diversity goes hand in hand with privileges of those who are considered as belong to a societal "default", which currently means a systemic bias in favour of being cis, male, heterosexual, white, middle or upper class, ablebodied, socialized as Christian and Euroamerican. The deviation from these norms correlates with exclusion mechanisms, and it is here where editormetric analyses could find a fundamentally important societal use. One might believe that these aspects may be easily analysable once we collect sufficient data, but a datafication of diversity may find its limitation when encountering issues of intersectionality (Cho et al. 2013; Crenshaw 2015). The framework of intersectionality states that a person's social and political identities create different modes of discrimination and privileges. Individuals or groups are marked as 'others' and thus experience discrimination based on actual or perceived characteristics. Those identities might refer to aspects of gender, racialization, class, sexual orientation and identification, religion, ability, and other assigned characteristics. The framework describes the 
overlap and concurrency of more than one of these categories of discrimination, which results in more than one axis and thus lead to multiple discriminations. If several of these attributes apply to a person, they can be multiply burdened. For example, a white woman is a target of sexism, but will never experience racism, in contrast to a disabled woman of colour who experiences sexism, racism, and ableism simultaneously. In addition, any measurement of this category of diversity is hampered by the fact that many of the categories involved are in large parts based on subjective, historical, and socially constructed characteristics linked to individual, institutional, and structural discrimination. All these issues and their intersections render it difficult to measure them objectively, including in meta-scientific and editormetric investigations, without oneself promoting 'forced outings' (Skinner-Thompson 2015), further otherings or similar discrimination processes.

To address this issue, one could use tools designed to automatically assign specific aspects related to diversity given a certain input. Gender guesser tools may serve as prime examples (Lin \& Serebrenik 2016; Sarawgi et al. 2011). While their practicability cannot be denied, they also carry fundamental deficiencies. The guesser tool, for instance, usually parses the persons' gender in terms of a binary system, and studies report on inequalities between female and male researchers within the scholarly publication process (Squazzoni et al. 2021). But this approach excludes a whole range of non-binary and trans identities; also a person whose name is coded as male might not be cis, but trans. In other words, the coded and the actual self-identified gender can differ widely. The same applies for aspects of so-called race, which is not a biological but a historical and racist social construct. This becomes clear when one and the same person can be coded as white, Person of cClor, or Black depending on the region's population they are referred to. To go even further, guessing a person's physical ability or their BIPoC (Black / Indigenous / People of Color) identity merely based on their names in the editorial board information is not possible at all.

All in all, automated and accurate estimations of diversity are not only technically difficult, but also ethically questionable. While a more promising venue might be to resort to self-reported criteria, there are ethical concerns here as well. A demand for detailed information on diversity is a double-edged sword: On the one hand, particularized metadata can provide an actual state of equality, detect biases, and thus serve as an inducement to make sustainable changes towards it. On the other hand, stipulating information on sensitive, private criteria such as gender, 
sexual preference and identification, racialization, ethnicity or physical abilities can result in a forced outing, such as when that outing is required before one occupies an editorial position at a scholarly journal. Contrary to the original goal, this would lead to even more discrimination. The value of an 'outing privacy' (Skinner-Thompson 2015) necessitates one to find other ways to measure diversity.

In summary, there is no easy solution of measuring this social-constructivist category of diversity based on metadata. It is even paradoxical that in a world in which discrimination persists, it can be even more stigmatizing to ask people to report actual or perceived characteristics on the basis of which they are marginalized. In addition, while diversity is an important issue, achieving it does not necessarily equal inclusivity; representation does not automatically lead to structural equality (Rose 1988). The mere addition of diverse researchers to editorial boards does not mean that scholarly publishing has become more equal. To achieve actual equality, the whole system needs a sustainable change in its structures.

This is certainly a key limitation inherent to Open Editors, or to any scientometric endeavour. This kind of societal diversity, while fundamental, persists, regardless of the scientific system's growing richness in metadata. This is where future reflections on meta-scientific datafication can further tread on in order to find an equitable, long-term solution.

\section{Conclusion}

There are multiple possibilities with which to proceed on the basis of the dataset thus collected, especially if it becomes linked with PIDs and other open datasets. To attain even more powerful studies and greater utility for research evaluation, it would be necessary to go beyond the bottom-up data collection approach used here and in related grassroots and crowdsourcing initiatives. Instead, publishers themselves should become conscious of the way they display their journals' editors and editorial boards. A uniform structure would enable scientometric investigations to an even more effective scale, enabling one to illuminate how knowledge (in-)equity fares in the landscape of scholarly publications with novel data. Many publishers have recently made their metadata on references available (thanks to the Initiative for Open Citations, or I4OC; Heibi et al. 2019), and have even opened up metadata on full abstract texts (thanks to the Initiative for Open Abstracts, or I4OA; Tay et al. 2020). Perhaps an Initiative for Open Editors, or I4OE, might also be called for. While only providing a small step, it may be 
an indispensable one towards the greater goal of achieving full and inclusive knowledge equity within the broader agenda of Open Science.

\section{Acknowledgements}

The authors thank Philipp Zumstein and Parthasarathi Mukhopadhyay for helpful comments, and Bianca Kramer for linking the dataset with ROR.

\section{Funding}

This work was supported by Wikimedia Deutschland e. V. within the Open Science Fellows Program.

\section{Contributor Statements}

- Andreas Nishikawa-Pacher: Conceptualization, Data curation, Methodology, Software, Writing original draft

- Tamara Heck: Conceptualization, Writing - review \& editing

- $\quad$ Kerstin Schoch: Conceptualization, Supervision, Writing - review \& editing

\section{References}

Altman, M., \& Cohen, P. N. (2021). 'Openness and Diversity in Journal Editorial Boards'. SocArXiv. DOI: 10.31235/osf.io/4nq97

Aryani, A., Fenner, M., Manghi, P., Mannocci, A., \& Stocker, M. (2020). 'Open Science Graphs Must Interoperate!'. Bellatreche L., Bieliková M., Boussaïd O., Catania B., Darmont J., Demidova E., Duchateau F., et al. (eds) ADBIS, TPDL and EDA 2020 Common Workshops and Doctoral Consortium, pp. 195-206. Cham: Springer International Publishing. DOI: 10.1007/978-3-030-55814-7_16

Baccini, A., \& Barabesi, L. (2010). 'Interlocking editorship. A network analysis of the links between economic journals', Scientometrics, 82/2: 365-89. DOI: 10.1007/s11192-009-0053-7

Baccini, A., Barabesi, L., Khelfaoui, M., \& Gingras, Y. (2019). 'Intellectual and social similarity among scholarly journals: An exploratory comparison of the networks of editors, authors and co-citations', Quantitative Science Studies, 1/1: 277-89. DOI: 10.1162/qss_a_00006

Becker, R. A., Wilks, A. R., Brownrigg, R., Minka, T. P., \& Deckmyn, A. (2018). maps: Draw Geographical Maps (R Package; CRAN R-Project).

Bishop, D. (2020). 'PEPIOPs - prolific editors who publish in their own publications'. BishopBlog. Retrieved February 25, 2021, from <http://deevybee.blogspot.com/2020/08/pepiops-prolific-editors-who-publish-in.html> 
Bornmann, L., \& Daniel, H.-D. (2009). 'Reviewer and editor biases in journal peer review: an investigation of manuscript refereeing at Angewandte Chemie International Edition', Research Evaluation, 18/4: 262-72. DOI: $10.3152 / 095820209 X 477520$

Brogaard, J., Engelberg, J., \& Parsons, C. A. (2014). 'Networks and productivity: Causal evidence from editor rotations', Journal of Financial Economics, 111/1: 251-70. DOI: 10.1016/j.jfineco.2013.10.006

Card, D., \& DellaVigna, S. (2020). 'What Do Editors Maximize? Evidence from Four Economics Journals', The Review of Economics and Statistics, 102/1: 195-217. DOI: 10.1162/rest_a_00839

Cho, S., Crenshaw, K. W., \& McCall, L. (2013). 'Toward a Field of Intersectionality Studies: Theory, Applications, and Praxis', Signs: Journal of Women in Culture and Society, 38/4: 785-810. DOI: 10.1086/669608

Crane, D. (1967). 'The Gatekeepers of Science: Some Factors Affecting the Selection of Articles for Scientific Journals', The American Sociologist, 2/4: 195-201.

Crenshaw, K. (2015). 'Demarginalizing the Intersection of Race and Sex: A Black Feminist Critique of Antidiscrimination Doctrine, Feminist Theory and Antiracist Politics', University of Chicago Legal Forum, $1989 / 1$.

Curry, C. L. (2017). 'SHERPA Services and SHERPA/RoMEO', Journal of Electronic Resources in Medical Libraries, 14/3-4: 135-8. DOI: 10.1080/15424065.2017.1368424

Downes, M. (2020). 'Thousands of Australian academics on the editorial boards of journals run by predatory publishers', Learned Publishing, 33/3: 287-95. DOI: https://doi.org/10.1002/leap.1297

Erfanmanesh, M., \& Morovati, M. (2018). 'Interlocking Editorships in Scientific Journals', Science and Engineering Ethics, 24/5: 1665-7. DOI: 10.1007/s11948-017-9971-6

Espin, J., Palmas, S., Carrasco-Rueda, F., Riemer, K., Allen, P. E., Berkebile, N., Hecht, K. A., et al. (2017). 'A persistent lack of international representation on editorial boards in environmental biology', PLOS Biology, 15/12: e2002760. DOI: 10.1371/journal.pbio.2002760

European Research Area and Innovation Committee. (2021). 'Research evaluation in a context of Open Science and gender equality'. European Union.

Feeney, M. K., Carson, L., \& Dickinson, H. (2019). 'Power in Editorial Positions: A Feminist Critique of Public Administration: Power in Editorial Positions: A Feminist Critique of Public Administration', Public Administration Review, 79/1: 46-55. DOI: 10.1111/puar.12950

Goyanes, M., \& de-Marcos, L. (2020). 'Academic influence and invisible colleges through editorial board interlocking in communication sciences: a social network analysis of leading journals', Scientometrics, 123/2: 791-811. DOI: 10.1007/s11192-020-03401-z 
Gutiérrez, J., \& López-Nieva, P. (2001). 'Are international journals of human geography really international?', Progress in Human Geography, 25/1: 53-69. DOI: 10.1191/030913201666823316

Haak, L. L., Fenner, M., Paglione, L., Pentz, E., \& Ratner, H. (2012). 'ORCID: a system to uniquely identify researchers', Learned Publishing, 25/4: 259-64. DOI: https://doi.org/10.1087/20120404

Harzing, A.-W., \& Metz, I. (2013). 'Practicing what We Preach', Management International Review, 53/2: 16987. DOI: $10.1007 / \mathrm{s} 11575-011-0124-\mathrm{x}$

Heibi, I., Peroni, S., \& Shotton, D. (2019). 'Software review: COCI, the OpenCitations Index of Crossref open DOI-to-DOI citations', Scientometrics, 121/2: 1213-28. DOI: 10.1007/s11192-019-03217-6

Hendricks, G., Tkaczyk, D., Lin, J., \& Feeney, P. (2020). 'Crossref: The sustainable source of community-owned scholarly metadata', Quantitative Science Studies, 1/1: 414-27. DOI: 10.1162/qss_a_00022

Hodgson, G. M., \& Rothman, H. (1999). 'The Editors and Authors of Economics Journals: A Case of Institutional Oligopoly?', The Economic Journal, 109: 165-86.

Horbach, S., \& Halffman, W. (2018). 'The changing forms and expectations of peer review', Research Integrity and Peer Review, 3/1: 8. DOI: 10.1186/s41073-018-0051-5

Horbach, S. P. J. M., \& Halffman, W. (2020). 'Journal Peer Review and Editorial Evaluation: Cautious Innovator or Sleepy Giant?', Minerva, 58/2: 139-61. DOI: 10.1007/s11024-019-09388-z

Horton, R. (2003). 'Medical journals: evidence of bias against the diseases of poverty', The Lancet, 361/9359: 712-3. DOI: 10.1016/S0140-6736(03)12665-7

Johnson, R., Watkinson, A., \& Mabe, M. (2018). 'The STM report: An overview of scientific and scholarly publishing'. International Association of Scientific, Technical and Medical Publishers.

Kamlah, J., \& Zumstein, P. (2021). scrape-editorial-board. GitHub.

Klebel, T., Reichmann, S., Polka, J., McDowell, G., Penfold, N., Hindle, S., \& Ross-Hellauer, T. (2020). 'Peer review and preprint policies are unclear at most major journals', bioRxiv, 2020.01.24.918995. DOI: $10.1101 / 2020.01 .24 .918995$

Laband, D. N., \& Piette, M. J. (1994). 'Favoritism versus Search for Good Papers: Empirical Evidence Regarding the Behavior of Journal Editors', Journal of Political Economy, 102/1: 194-203. DOI: 10.1086/261927

Lammey, R. (2020). 'Solutions for identification problems: a look at the Research Organization Registry', Science Editing, 7/1: 65-9. DOI: 10.6087/kcse.192

Lin, B., \& Serebrenik, A. (2016). 'Recognizing gender of stack overflow users'. Proceedings of the 13th International Conference on Mining Software Repositories, MSR '16, pp. 425-9. New York, NY, USA: Association for Computing Machinery. DOI: 10.1145/2901739.2901777 
Marchitelli, A., Galimberti, P., Bollini, A., \& Mitchell, D. (2017). 'Improvement of editorial quality of journals indexed in DOAJ: a data analysis', Italian Journal of Library, Archives, and Information Science, 8/1: 1-21. DOI: 10.4403/jlis.it-12052

Masic, I. (2017). 'Predatory Publishing - Experience with OMICS International', Medical Archives, 71/5: 3047. DOI: $10.5455 /$ medarh.2017.71.304-307

Mazov, N. A., \& Gureev, V. N. (2016). 'The editorial boards of scientific journals as a subject of scientometric research: A literature Review', Scientific and Technical Information Processing, 43/3: 144-53. DOI: $10.3103 / \mathrm{S} 0147688216030035$

McGinty, S. (1999). Gatekeepers of Knowledge: Journal Editors in the Sciences and the Social Sciences. Westport, Connecticut: Greenwood.

Mendonça, S., Pereira, J., \& Ferreira, M. E. (2018). 'Gatekeeping African studies: what does "editormetrics" indicate about journal governance?', Scientometrics, 117/3: 1513-34. DOI: 10.1007/s11192-018-2909-1

Michaud, F. (2022). 'A Registry of Editorial Boards: A new trust signal for scholarly communications?'. Crossref. Retrieved May 11, 2022, from <https://www.crossref.org/blog/a-registry-of-editorial-boards-a-new-trust-signalfor-scholarly-communications/>

Nguyen, V. M., Haddaway, N. R., Gutowsky, L. F. G., Wilson, A. D. M., Gallagher, A. J., Donaldson, M. R., Hammerschlag, N., et al. (2015). 'How Long Is Too Long in Contemporary Peer Review? Perspectives from Authors Publishing in Conservation Biology Journals', PLOS ONE, 10/8: e0132557. DOI: 10.1371/journal.pone.0132557

Nicholas, D., Herman, E., Jamali, H. R., Abrizah, A., Boukacem-Zeghmouri, C., Xu, J., Rodríguez-Bravo, B., et al. (2020). 'Millennial researchers in a metric-driven scholarly world: An international study', Research Evaluation, 29/3: 263-74. DOI: 10.1093/reseval/rvaa004

Nosek, B. A., Alter, G., Banks, G. C., Borsboom, D., Bowman, S. D., Breckler, S. J., Buck, S., et al. (2015). 'Promoting an open research culture', Science, 348/6242: 1422-5. DOI: 10.1126/science.aab2374

Okagbue, H. I., Atayero, A. A., Adamu, M. O., Bishop, S. A., Oguntunde, P. E., \& Opanuga, A. A. (2018). 'Exploration of editorial board composition, Citescore and percentiles of Hindawi journals indexed in Scopus', Data in Brief, 19: 743-52. DOI: 10.1016/j.dib.2018.05.066

Pacher, A. (2022). andreaspacher/openeditors (GitHub).

- (2021). 'A List of Academic Publishers and their Scholarly Journals: A Webscraping Approach'. SocArXiv. DOI: $10.31235 / \mathrm{osf} .10 / 56 \mathrm{~b} 28$

Petersen, J. (2017). 'How innovative are editors?: evidence across journals and disciplines', Research Evaluation, 26/3: 256-68. DOI: 10.1093/reseval/rvx015 
Petersen, J., Hattke, F., \& Vogel, R. (2017). 'Editorial governance and journal impact: a study of management and business journals', Scientometrics, 112/3: 1593-614. DOI: 10.1007/s11192-017-2434-7

Pollock, D. (2022). 'News \& Views: Publishers and Market Consolidation - Part 1 of 2'. Delta Think. Retrieved July 6, 2022, from <https://deltathink.com/news-views-publishers-and-market-consolidation-part-1-of-2/>

Priem, J., Piwowar, H., \& Orr, R. (2022). 'OpenAlex: A fully-open index of scholarly works, authors, venues, institutions, and concepts'. arXiv. DOI: 10.48550/arXiv.2205.01833

Rose, J. (1988). 'Margaret Thatcher and Ruth Ellis', New Formations, 6: 3-29.

Ruiter-Lopez, L., Lopez-Leon, S., \& Forero, D. A. (2019). 'Predatory journals: Do not judge journals by their Editorial Board Members', Medical Teacher, 41/6: 691-6. DOI: 10.1080/0142159X.2018.1556390

Safder, I., Hassan, S.-U., Visvizi, A., Noraset, T., Nawaz, R., \& Tuarob, S. (2020). 'Deep Learning-based Extraction of Algorithmic Metadata in Full-Text Scholarly Documents', Information Processing \& Management, 57/6: 102269. DOI: 10.1016/j.ipm.2020.102269

Sarawgi, R., Gajulapalli, K., \& Choi, Y. (2011). 'Gender attribution: tracing stylometric evidence beyond topic and genre'. Proceedings of the Fifteenth Conference on Computational Natural Language Learning, CoNLL '11, pp. 78-86. USA: Association for Computational Linguistics.

Scimago Journal \& Country Rank. (2022). 'International Science Ranking'. Retrieved July 6, 2022, from <https://www.scimagojr.com/countryrank.php>

Simón, A. (2016). 'Pitfalls of Predatory Journals: A Personal Account', Comprehensive Psychology, 5: 2165222816631691. DOI: $10.1177 / 2165222816631691$

Skinner-Thompson, S. (2015). 'Outing Privacy’, Northwestern University Law Review, 110/1: 159-222.

Squazzoni, F., Bravo, G., Farjam, M., Marusic, A., Mehmani, B., Willis, M., Birukou, A., et al. (2021). 'Peer review and gender bias: A study on 145 scholarly journals', Science Advances, 7/2: eabd0299. DOI: 10.1126/sciadv.abd0299

Stegmaier, M., Palmer, B., \& van Assendelft, L. (2011). 'Getting on the Board: The Presence of Women in Political Science Journal Editorial Positions', PS: Political Science \& Politics, 44/04: 799-804. DOI: $10.1017 / \mathrm{S} 1049096511001284$

Tay, A., Kramer, B., \& Waltman, L. (2020). 'Why openly available abstracts are important - overview of the current state of affairs'. Medium. Retrieved February 25, 2021, from <https://medium.com/a-academic-librariansthoughts-on-open-access/why-openly-available-abstracts-are-important-overview-of-the-current-state-of-affairsbb7bde1ed751>

Topaz, C. M., \& Sen, S. (2016). 'Gender Representation on Journal Editorial Boards in the Mathematical Sciences', PLOS ONE, 11/8: e0161357. DOI: 10.1371/journal.pone.0161357 
Wickham, H. (2020). rvest: Easily Harvest (Scrape) Web Pages (R Package).

Wilson, M. C., \& Knutsen, C. H. (online first). 'Geographical Coverage in Political Science Research', Perspectives on Politics, 1-16. DOI: 10.1017/S1537592720002509

Wong, V. S. S., \& Callaham, M. L. (2012). 'Medical journal editors lacked familiarity with scientific publication issues despite training and regular exposure', Journal of Clinical Epidemiology, 65/3: 247-52. DOI: 10.1016/j.jclinepi.2011.08.003

Wu, D., Lu, X., Li, J., \& Li, J. (2020). 'Does the institutional diversity of editorial boards increase journal quality? The case economics field', Scientometrics, 124/2: 1579-97. DOI: 10.1007/s11192-020-03505-6

Xie, Y., Wu, Q., \& Li, X. (2019). 'Editorial team scholarly index (ETSI): an alternative indicator for evaluating academic journal reputation', Scientometrics, 120/3: 1333-49. DOI: 10.1007/s11192-019-03177-x

Xu, B., Meng, H., Qin, S., Liu, Y., Li, Z., Cao, J., Lin, Y., et al. (2019). 'How international are the editorial boards of leading spine journals? A STROBE-compliant study', Medicine, 98/5: e14304. DOI: 10.1097/MD.0000000000014304

Yoon, A. H. (2013). 'Editorial Bias in Legal Academia', Journal of Legal Analysis, 5/2: 309-38. DOI: 10.1093/jla/lat005

Zhang, L., Sun, B., Jiang, L., \& Huang, Y. (2021). 'On the relationship between interdisciplinarity and impact: Distinct effects on academic and broader impact', Research Evaluation, rvab007. DOI: 10.1093/reseval/rvab007

Zhang, T., Shi, J., \& Situ, L. (2021). 'The correlation between author-editorial cooperation and the author's publications in journals', Journal of Informetrics, 15/1: 101123. DOI: 10.1016/j.joi.2020.101123 